\title{
EGFR-tyrosine kinase inhibitor treatment in a patient with advanced non-small cell lung cancer and concurrent exon 19 and 21 EGFR mutations: A case report and review of the literature
}

\author{
YANG YANG $^{1}$, BIAO ZHANG $^{2}$, RUTIAN LI $^{1}$, BAORUI LIU $^{1}$ and LIFENG WANG ${ }^{1}$ \\ ${ }^{1}$ The Comprehensive Cancer Center of Drum-Tower Hospital, \\ Nanjing University Medical School and Clinical Cancer Institute of Nanjing University; ${ }^{2}$ Department of \\ Pathology, Drum-Tower Hospital, Nanjing University Medical School, Nanjing, Jiangsu 210008, P.R. China
}

Received January 23, 2015; Accepted March 9, 2016

DOI: $10.3892 / 01.2016 .4409$

\begin{abstract}
Epidermal growth factor receptor-tyrosine kinase inhibitors (EGFR-TKIs) are considered to be effective treatments for advanced non-small cell lung cancer (NSCLC) patients with sensitizing EGFR mutations, including exon 19 deletion and exon 21 L858R mutations. However, with the development of EGFR mutation detection assays, patients with complex EGFR mutations are emerging, and their response to EGFR-TKIs remains unclear. The present study reports a case of a 62-year-old, non-smoking female patient with advanced NSCLC, presenting with concurrent EGFR 19+21 sensitizing mutations, who had a poor response to the first-line EGFR-TKI erlotinib and succumbed 5 months subsequent to diagnosis. Furthermore, the present study performed a literature review, and 18 patients with complex EGFR 19+21 mutations that had received EGFR-TKIs were identified. The majority of these patients responded well to EGFR-TKIs. To the best of our knowledge, the present case is the first to report a patient with lung adenocarcinoma with complex EGFR 19+21 sensitizing mutations that had a poor clinical response to a first-line EGFR-TKI. Despite the $70 \%$ response rate of sensitizing EGFR-mutant NSCLCs to EGFR-TKIs, there is still a proportion of patients that experience de novo resistance, and heterogeneity is likely to be important in this resistance mechanism. Therefore, comprehensive genomic detection assays and multi-targeted therapies for patients with NSCLC with complex EGFR mutations require additional investigation.
\end{abstract}

Correspondence to: Professor Lifeng Wang, The Comprehensive Cancer Center of Drum-Tower Hospital, Nanjing University Medical School and Clinical Cancer Institute of Nanjing University, 321 Zhongshan Road, Nanjing, Jiangsu 210008, P.R. China

E-mail: lifengwang@nju.edu.cn

Key words: EGFR mutation, complex mutations, EGFR tyrosine kinase inhibitors, non-small cell lung cancer

\section{Introduction}

Lung cancer remains one of the most common types of cancer worldwide (1.8 million novel cases were diagnosed in 2012, $13 \%$ of the total cancer cases diagnosed), and it was the leading cause of cancer-associated mortality in 2012 (1.59 million mortalities; $19.4 \%$ of all cancer-associated mortalities in 2012) (1). Conventional platinum-based chemotherapy has reached a plateau in improving patient survival and disease control obtained with classic doublet chemotherapy in patients with advanced lung cancer is usually restricted to a few months (2-4). Fortunately, developments in molecular biology have attracted attention to the molecular subtypes of lung cancer, resulting in great improvements in understanding the disease, including the identification of mutations in the epidermal growth factor receptor (EGFR).

The majority of EGFR mutations are located at exon 19, which are deletions (Del-19), and exon 21 (L858R), and mutations at these sites account for 45 and $40 \%$ of all EGFR mutations, respectively (5). These mutations are considered to be sensitizing mutations that confer sensitivity to EGFR-tyrosine kinase inhibitors (EGFR-TKIs), including gefitinib and erlotinib (6-8). Clinical trials have demonstrated that EGFR-TKIs are associated with a significantly increased response rate (RR) and progress free survival (PFS) rate for patients harboring EGFR sensitizing mutations, as compared with chemotherapy alone $(9,10)$. To date, the detection of EGFR mutations has been performed prior to the treatment of advanced non-squamous NSCLC, while an increasing number of rare types of EGFR mutations have been discovered, which are not only limited to the mutation of a single exon, but the concurrence of two mutations on different exons, primarily exons $18-21$, in a single tumor sample $(11,12)$. These mutations are termed 'complex mutations'. However, the response of patients harboring the complex EGFR mutations to first-line EGFR-TKIs remains unclear. The present study reports a case of a patient with advanced NSCLC and complex EGFR mutations, and the patient's response to first-line EGFR-TKI treatment. Written informed consent was obtained from the patient for the publication of the present study. 
A

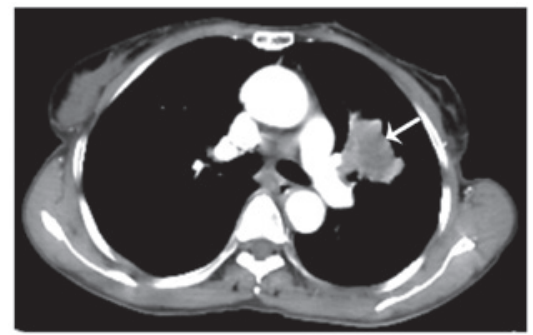

C

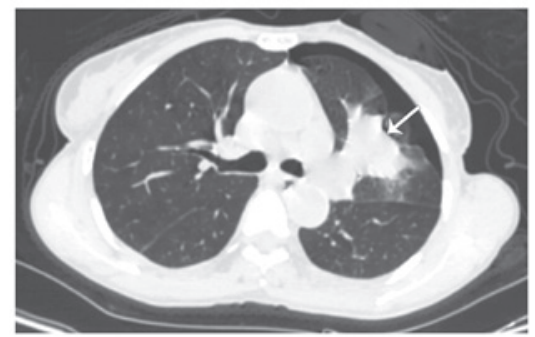

B

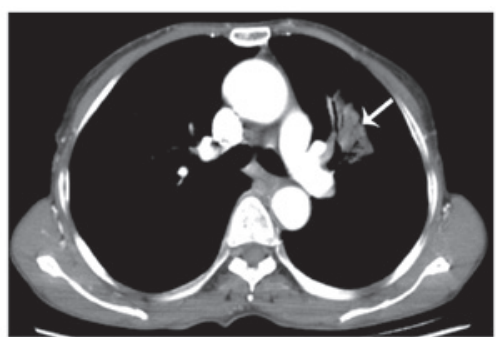

D

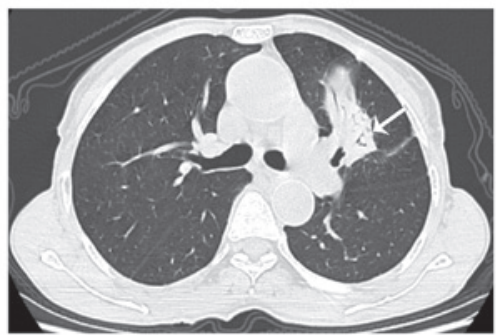

Figure 1. Chest computed tomography scans. Presence of a left upper lobe primary mass with multiple small pulmonary nodules in both lungs was observed prior to erlotinib treatment; a left upper lobe primary mass was identified on the (A) mediastinal window and (B) pulmonary window, respectively (arrows). Following 8 weeks of erlotinib treatment the mass had shrunk on the (C) mediastinal and (D) pulmonary windows, respectively (arrows).

A

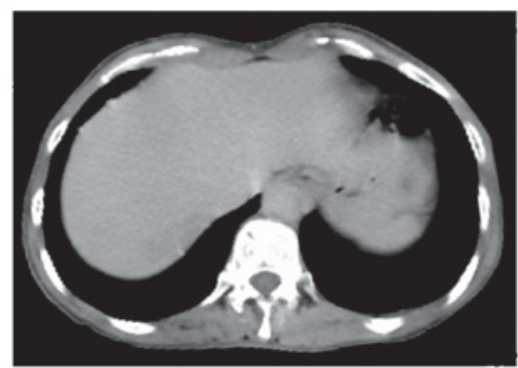

$\mathbf{C}$

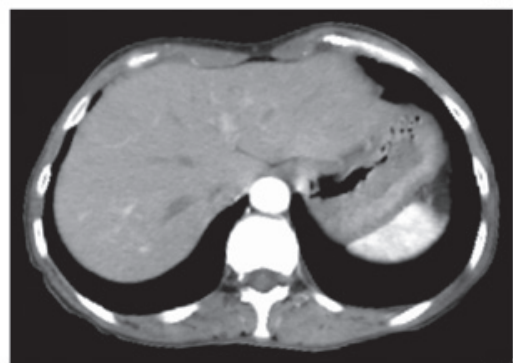

$\mathbf{E}$

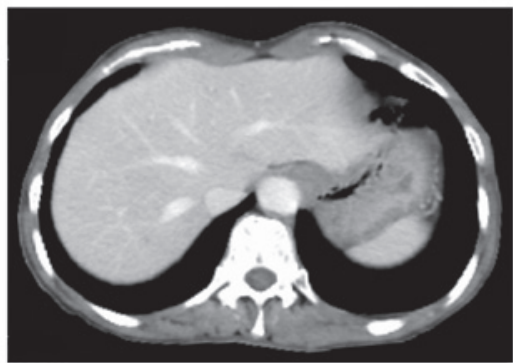

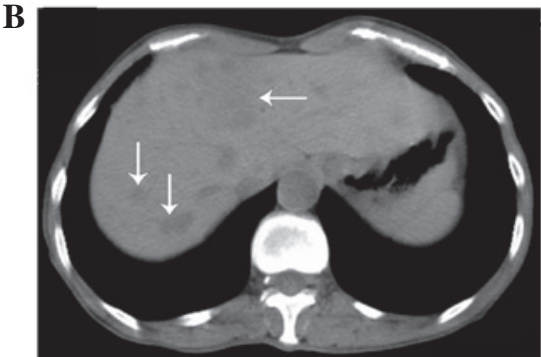

D

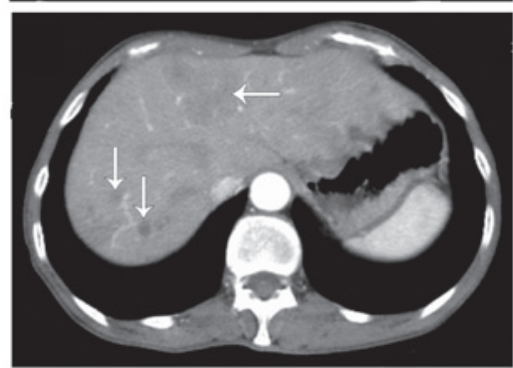

$\mathbf{F}$

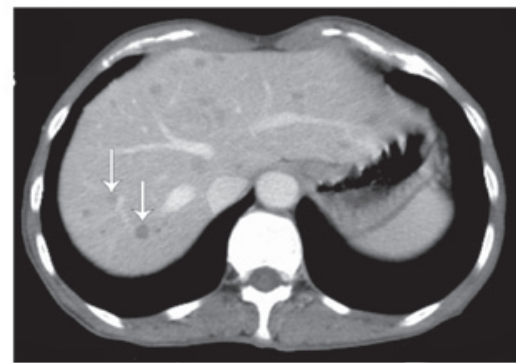

Figure 2. Hepatic computed tomography scans. Absence of hepatic metastasis prior to erlotinib treatment was observed on a (A) plain, (B) venous phase and (C) arterial phase scan (arrows). Presence of hepatic metastasis following 8 weeks of erlotinib treatment was observed on a (D) plain, (E) venous phase and (F) arterial phase scan (arrows).

\section{Case report}

On March 10, 2014, a 62-year-old, non-smoking woman with an Eastern Cooperative Oncology Group Performance Status score of 2 (13) presented to the Department of Oncology, Comprehensive Cancer Center of Drum-Tower Hospital (Nanjing, China) with a cough that had been ongoing for
2 months. Computed tomography (CT; Discovery CT750 HD; GE Healthcare Life Sciences, Shanghai, China) revealed a primary mass in the left upper lobe of the lung (Fig. 1A and B), with multiple small pulmonary nodules (maximum diameter, $4 \mathrm{~mm}$ ) observed bilaterally. A CT-guided fine needle aspiration biopsy of the primary lesion was performed on the left lung, which revealed the presence of a middle-differentiated 
Table I. Characteristics of 18 patients with EGFR Del-19 + L858R mutations that were treated with EGFR-tyrosine kinase inhibitors.

\begin{tabular}{|c|c|c|c|c|c|c|c|c|}
\hline Patient & Author, year & Gender & $\begin{array}{l}\text { Smoking } \\
\text { status }\end{array}$ & Histology & Response & $\begin{array}{l}\text { PFS, } \\
\text { months }\end{array}$ & $\begin{array}{l}\text { OS, } \\
\text { months }\end{array}$ & (Ref.) \\
\hline 1 & Zhang et al, 2007 & M & Yes & Adenocarcinoma & $\mathrm{CR}$ & 18 & 20 & $(17)$ \\
\hline 2 & Zhang et al, 2007 & M & No & Adenocarcinoma & PR & $>19$ & $>19$ & $(17)$ \\
\hline 3 & Zhang et al, 2007 & M & Yes & Adenocarcinoma & NE & 2 & 2 & $(17)$ \\
\hline 4 & Masago et al, 2009 & $\mathrm{~F}$ & No & Adenocarcinoma & PR & 14 & 23 & $(18)$ \\
\hline 5 & Masago et al, 2009 & $\mathrm{~F}$ & No & Adenocarcinoma & PD & 1 & 11 & $(18)$ \\
\hline 6 & Masago et al, 2009 & $\mathrm{~F}$ & No & Adenocarcinoma & PR & 11 & 11 & $(18)$ \\
\hline 7 & Masago et al, 2009 & $\mathrm{~F}$ & No & Adenocarcinoma & PD & 2 & $>39$ & $(18)$ \\
\hline 8 & Masago et al, 2010 & M & No & Adenocarcinoma & NE & $>2$ & $>2$ & (19) \\
\hline 9 & Keam et al, 2014 & $\mathrm{~F}$ & No & Adenocarcinoma & PR & 4 & 12 & $(20)$ \\
\hline 10 & Peng et al, 2014 & M & No & Adenocarcinoma & SD & 8 & $>8$ & $(21)$ \\
\hline 11 & Peng et al, 2014 & $\mathrm{~F}$ & No & $\begin{array}{l}\text { Adenosquamous } \\
\text { carcinoma }\end{array}$ & PR & 15 & $>58$ & (21) \\
\hline 12 & Hata et al, 2010 & $\mathrm{~F}$ & No & Adenocarcinoma & $\mathrm{CR}$ & 31 & $>41$ & $(22)$ \\
\hline 13 & Hata et al, 2010 & $\mathrm{~F}$ & No & Adenocarcinoma & PR & 7 & $>33$ & $(22)$ \\
\hline 14 & Hata et al, 2010 & $\mathrm{~F}$ & Yes & Adenocarcinoma & PR & $>23$ & $>23$ & $(22)$ \\
\hline 15 & Hata et al, 2010 & M & Yes & Adenocarcinoma & PR & 12 & $>13$ & (22) \\
\hline 16 & Hata et al, 2010 & M & Former & Adenocarcinoma & PR & $>10$ & $>10$ & (22) \\
\hline 17 & Hata et al, 2010 & M & No & Adenocarcinoma & PR & $>9$ & $>9$ & (22) \\
\hline 18 & Hata et al, 2010 & M & Yes & Adenocarcinoma & SD & $>13$ & $>13$ & (22) \\
\hline
\end{tabular}

Patients were assessed based on the Response Evaluation Criteria in Solid Tumors (15). EGFR, epidermal growth factor receptor; PFS, progress free survival; OS, overall survival; M, male; F, female; Del-19, deletion on exon 19; L858R, mutation on exon 21; NE, not evaluated; $\mathrm{CR}$, complete response; PR, partial response; $\mathrm{SD}$, stable disease; $\mathrm{PD}$, progressive disease.

adenocarcinoma. EGFR mutation analysis was performed on the biopsied tissue within exons 18 and 21. EGFR mutations were detected by amplification refractory mutation system in multiple quantitative polymerase chain reaction analysis with the Human EGFR Mutation Detection kit (YuanQi Bio-Pharmaceutical Co., Ltd., Shanghai, China), as previously described (14), which demonstrated a co-mutant of Del-19 (del 2239_2248+insC) and L858R. In addition, anaplastic lymphoma kinase rearrangement analysis was performed using fluorescence in situ hybridization, with negative results. The patient was orally administered erlotinib, at a dose of $150 \mathrm{mg} / \mathrm{day}$. Two months later, no considerable relief of the cough was noted; however, a CT scan revealed that the primary lung mass had shrunk (Fig. 1C and D), but the bilateral multiple pulmonary nodules remained. In addition, prior to erlotinib treatment there was no hepatic metastases (Fig. 2A-C); however, following treatment multiple hepatic metastases were observed (Fig. 2D-F). Based on the Response Evaluation Criteria in Solid Tumors (RECIST) (15), the treatment response of the patient was assessed as progressive disease (PD). The patient refused to undergo a biopsy of the liver. Treatment with erlotinib was stopped when PD was detected, and 2 cycles ( 3 weeks/cycle) of chemotherapy with pemetrexed $\left(500 \mathrm{mg} / \mathrm{m}^{2}\right)$ plus cisplatin $\left(75 \mathrm{mg} / \mathrm{m}^{2}\right)$ were administered to the patient intravenously. However, the hepatic metastases continued to progress under the assessment of CT scans, which were performed monthly. The patient succumbed
2 months subsequent to the detection of $\mathrm{PD}$, with the best supportive care possible. The patient's overall survival was $\sim 5.3$ months.

\section{Discussion}

The use of first-line EGFR-TKIs in NSCLC patients with EGFR sensitizing mutations has been demonstrated to be superior to chemotherapy in terms of PFS, RR and quality of life; however, previous phase III clinical trials primarily enrolled patients harboring common EGFR mutations, including exon 19 deletion or exon 21 L858R (16). For patients who exhibit uncommon mutations, particularly complex 19+21 mutations, the efficacy of first-line EGFR-TKIs remains unknown. Despite the fact that the present patient harbored Del-19 and L858R, which are sensitizing EGFR mutations, the patient experienced PD following treatment with first-line erlotinib. In order to acquire an improved understanding of this, the present study performed a comprehensive search of relevant studies published on the PubMed database (www.ncbi. nlm.nih.gov/pubmed) using keywords, including 'complex mutations', 'double mutations', 'compound mutations', 'multiple mutations', 'rare mutations' and 'uncommon mutations', with 'EGFR' added to each keyword. All studies with relevant abstracts (1,949 abstracts) were retrieved first, and the full texts of those that were considered valuable, including studies that contained patients carrying complex, double, 
compound, multiple, rare or uncommon mutations of EGFR, were carefully reviewed (27 studies). Relevant references from the searched studies ( 6 references) were also reviewed.

In total, 18 patients with EGFR Del-19 + L858R mutations that received EGFR-TKIs were identified between January 2002 and January 2015 (Table I) (17-22). Of these 18, 16 patients were assessed based on RECIST (15) and 2 patients were not evaluated. The 18 patients presented in Table I exhibited the following responses: 2 (11.1\%), complete response; 10 (55.6\%), partial response; 2 (11.1\%), stable disease; 2 (11.1\%), PD; and 2 patients $(11.1 \%)$ that were not evaluated experienced a relief of their symptoms. Only 2 out of the 18 patients experienced PD following the initiation of EGFR-TKIs, and these patients were administered EGFR-TKIs as second-line treatment, following first-line carboplatin and paclitaxel regimens. Compared with patients harboring EGFR mutations that were administered first-line EGFR-TKIs, those who received EGFR-TKIs as second-line treatment following platinum-based chemotherapy exhibited a lower response rate $(23,24)$. A study by Bai et al (25) demonstrated that prior chemotherapy may reduce the EGFR mutation rate in the plasma, suggesting that the poor response of the 2 aforementioned patients with PD may be associated with the first-line chemotherapy each received.

The present patient had concurrent EGFR19+21 sensitizing mutations and received EGFR-TKI as a first-line treatment; however, the patient had PD following treatment. Previously, genetic heterogeneity of tumors has received considerable attention. Studies on clear cell renal carcinoma have demonstrated substantial intratumor heterogeneity of mutations in known cancer genes $(26,27)$, which suggests that a single biopsy of a tumor may be inadequate to detect all cancer gene mutations, resulting in inconsistencies between detection and clinical efficacy. By contrast, a recent study by Zhang et al (28) on lung adenocarcinoma demonstrated that $76 \%$ of mutations were detected in various regions of the same tumor, indicating that single-region biopsy may compromise the intratumor heterogeneity to an acceptable extent, therefore identifying the majority of cancer gene mutations in localized lung adenocarcinomas.

In the present case, the EGFR gene detection assay on the core biopsy tissue of the primary lesion in the left lung revealed Del-19 and L858R mutations. Notably, following the initiation of EGFR-TKI treatment the primary lung mass shrunk and hepatic metastases appeared extensively. The present study hypothesizes that the genomic features of the hepatic metastases varied from those of the primary tumor, indicating that intertumor heterogeneity may be responsible for the PD observed in the present patient. In addition, de Bruin et al (29) revealed evidence of branched evolution with driver mutations arising prior to and following subclonal diversification, which supports the hypothesis of the present authors. Considering that the majority of NSCLC driver mutations occur in the early phases of tumor evolution (29), the Del-19 + L858R mutations of the present patient may have been truncal mutations of the ancestral clone, existing only in the primary lung lesion. With regard to the hepatic metastases, it is likely that they consisted of sectional and predominant subclones with branch gene alternations that confer de novo resistance to EGFR-TKIs, including phosphatidylinositol-4,5-bisphosphate 3-kinase catalytic subunit $\alpha$, phosphatase and tensin homolog, protein kinase B and serine/threonine kinase 11 alterations, c-met amplification, hepatocyte growth factor overexpression and Kirsten ras mutations (30-34). Under circumstances when re-biopsy is not feasible, comprehensive genomic detection and multi-targeted therapies may be used. It has been suggested that liquid biopsy may reveal relatively comprehensive gene alternations and provide predictive information on the identification of therapeutic targets and resistance mechanisms (35).

To the best of our knowledge, this is the first study of a treatment-naive NSCLC patient harboring complex EGFR 19+21 sensitizing mutations presenting with de novo resistance to first-line EGFR-TKI treatment. Previous studies have suggested that NSCLC patients harboring complex EGFR 19+21 mutations usually have good response to EGFR-TKIs; however, in order to understand the complexity of EGFR mutations and determine the efficacy of EGFR-TKIs against them, large-scale clinical trials are required.

\section{Acknowledgements}

The present study was supported by the Health Scientific Research Project of Jiangsu Province, Nanjing, China (grant no. H201235) and Key Project of Nanjing Medical Science and Technology Development Foundation, Nanjing, China (grant no. ZKX12012).

\section{References}

1. Ferlay JSI, Ervik M, Dikshit R, Eser S, Mathers C, Rebelo M, Parkin DM, Forman D and Bray F: GLOBOCAN 2012 v1.0, Cancer Incidence and Mortality Worldwide: IARC CancerBase No. 11 (Internet). International Agency for Research on Cancer, Lyon, France, 2013. http://globocan.iarc.fr. Accessed January 23, 2015.

2. Schiller JH, Harrington D, Belani CP, Langer C, Sandler A, Krook J, Zhu J and Johnson DH; Eastern Cooperative Oncology Group: Comparison of four chemotherapy regimens for advanced non-small-cell lung cancer. N Engl J Med 346: 92-98, 2002.

3. Scagliotti GV, De Marinis F, Rinaldi M, Crinò L, Gridelli C, Ricci S, Matano E, Boni C, Marangolo M, Failla G, et al: Phase III randomized trial comparing three platinum-based doublets in advanced non-small-cell lung cancer. J Clin Oncol 20: 4285-4291, 2002.

4. Fossella F, Pereira JR, von Pawel J, Pluzanska A, Gorbounova V, Kaukel E, Mattson KV, Ramlau R, Szczesna A, Fidias P, et al: Randomized, multinational, phase III study of docetaxel plus platinum combinations versus vinorelbine plus cisplatin for advanced non-small-cell lung cancer: The TAX 326 study group. J Clin Oncol 21: 3016-3024, 2003.

5. Shigematsu H, Lin L, Takahashi T, Nomura M, Suzuki M, Wistuba II, Fong KM, Lee H, Toyooka S and Shimizu N: Clinical and biological features associated with epidermal growth factor receptor gene mutations in lung cancers. J Natl Cancer Inst 97: 339-346, 2005

6. Lynch TJ, Bell DW, Sordella R, Gurubhagavatula S, Okimoto RA, Brannigan BW, Harris PL, Haserlat SM, Supko JG, Haluska FG, et al: Activating mutations in the epidermal growth factor receptor underlying responsiveness of non-small-cell lung cancer to gefitinib. N Engl J Med 350: 2129-2139, 2004.

7. Paez JG, Jänne PA, Lee JC, Tracy S, Greulich H, Gabriel S, Herman P, Kaye FJ, Lindeman N, Boggon TJ, et al: EGFR mutations in lung cancer: Correlation with clinical response to gefitinib therapy. Science 304: 1497-1500, 2004.

8. Pao W, Miller V, Zakowski M, Doherty J, Politi K, Sarkaria I, Singh B, Heelan R, Rusch V, Fulton L, et al: EGF receptor gene mutations are common in lung cancers from 'never smokers' and are associated with sensitivity of tumors to gefitinib and erlotinib. Proc Natl Acad Sci USA 101: 13306-13311, 2004.

9. Gerber DE, Gandhi L and Costa DB: Management and future directions in non-small cell lung cancer with known activating mutations. Am Soc Clin Oncol Educ Book e353-e365, 2014. 
10. Lee JY, Lim SH, Kim M, Kim S, Jung HA, Chang WJ, Choi MK, Hong JY, Lee SJ, Sun JM, et al: Is there any predictor for clinical outcome in EGFR mutant NSCLC patients treated with EGFR TKIs? Cancer Chemother Pharmacol 73: 1063-1070, 2014.

11. Huang SF, Liu HP, Li LH, Ku YC, Fu YN, Tsai HY, Chen YT, Lin YF, Chang WC, Kuo HP, et al: High frequency of epidermal growth factor receptor mutations with complex patterns in non-small cell lung cancers related to gefitinib responsiveness in Taiwan. Clin Cancer Res 10: 8195-8203, 2004.

12. Hsieh MH, Fang YF, Chang WC, Kuo HP, Lin SY, Liu HP Liu CL, Chen HC, Ku YC, Chen YT, et al: Complex mutation patterns of epidermal growth factor receptor gene associated with variable responses to gefitinib treatment in patients with non-small cell lung cancer. Lung Cancer 53: 311-322, 2006.

13. Oken MM, Creech RH, Tormey DC, Horton J, Davis TE, McFadden ET and Carbone PP: Toxicity and response criteria of the Eastern Cooperative Oncology Group. Am J Clin Oncol 5: 649-655, 1982

14. Huang SW, Ho CF, Chan KW, Cheng MC, Shien JH, Liu HJ and Wang CY: The genotyping of infectious bronchitis virus in Taiwan by a multiplex amplification refractory mutation system reverse transcription polymerase chain reaction. J Vet Diagn Invest 26: 721-733, 2014.

15. Therasse P, Arbuck SG, Eisenhauer EA, Wanders J, Kaplan RS, Rubinstein L, Verweij J, Van Glabbeke M, van Oosterom AT and Christian MC: New guidelines to evaluate the response to treatment in solid tumors. European organization for research and treatment of cancer, national cancer institute of the united states, national cancer institute of Canada. J Natl Cancer Inst 92 205-216, 2000.

16. Rosell R, Carcereny E, Gervais R, Vergnenegre A, Massuti B, Felip E, Palmero R, Garcia-Gomez R, Pallares C, Sanchez JM, et al; Spanish Lung Cancer Group in collaboration with Groupe Français de Pneumo-Cancérologie and Associazione Italiana Oncologia Toracica: Erlotinib versus standard chemotherapy as first-line treatment for European patients with advanced EGFR mutation-positive non-small-cell lung cancer (EURTAC): A multicentre, open-label, randomised phase 3 trial. Lancet Oncol 13: 239-246, 2012

17. Zhang GC, Lin JY, Wang Z, Zhou Q, Xu CR, Zhu JQ, Wang K, Yang XN, Chen G, Yang JJ, et al: Epidermal growth factor receptor double activating mutations involving both exons 19 and 21 exist in Chinese non-small cell lung cancer patients. Clin Oncol (R Col Radiol) 19: 499-506, 2007.

18. Masago K, Fujita S, Kim YH, Ichikawa M, Hatachi Y, Fukuhara A, Nagai H, Irisa K, Mio T and Mishima M: Epidermal growth factor receptor (EGFR) double-activating somatic mutations in exons 19 and 21 in Japanese non-small cell lung cancer patients. Cancer Genet Cytogenet 195: 179-182, 2009.

19. Masago K, Togashi Y, Fukudo M, Terada T, Irisa K, Sakamori Y, Fujita S, Kim YH, Mio T and Inui K: Good clinical response to erlotinib in a non-small cell lung cancer patient harboring multiple brain metastases and a double active somatic epidermal growth factor gene mutation. Case Rep Oncol 3: 98-105, 2010.

20. Keam B, Kim DW, Park JH, Lee JO, Kim TM, Lee SH, Chung DH and Heo DS: Rare and complex mutations of epidermal growth factor receptor and efficacy of tyrosine kinase inhibitor in patients with non-small cell lung cancer. Int J Clin Oncol 19 : 594-600, 2014

21. Peng L, Song ZG and Jiao SC: Efficacy analysis of tyrosine kinase inhibitors on rare non-small cell lung cancer patients harboring complex EGFR mutations. Sci Rep 4: 6104, 2014.
22. Hata A, Yoshioka H, Fujita S, Kunimasa K, Kaji R, Imai Y, Tomii K, Iwasaku M, Nishiyama A and Ishida T: Complex mutations in the epidermal growth factor receptor gene in non-small cell lung cancer. J Thorac Oncol 5: 1524-1528, 2010.

23. Shepherd FA, Rodrigues Pereira J, Ciuleanu T, Tan EH, Hirsh V, Thongprasert S, Campos D, Maoleekoonpiroj S, Smylie M, Martins R, et al: Erlotinib in previously treated non-small-cell lung cancer. N Engl J Med 353: 123-132, 2005.

24. Thatcher N, Chang A, Parikh P, Rodrigues Pereira J, Ciuleanu T, von Pawel J, Thongprasert S, Tan EH, Pemberton K and Archer V: Gefitinib plus best supportive care in previously treated patients with refractory advanced non-small-cell lung cancer: Results from a randomised, placebo-controlled, multicentre study (iressa survival evaluation in lung cancer). Lancet 366: 1527-1537, 2005.

25. Bai H, Wang Z, Chen K, Zhao J, Lee JJ, Wang S, Zhou Q, Zhuo M, Mao L, An T, et al: Influence of chemotherapy on EGFR mutation status among patients with non-small-cell lung cancer. J Clin Oncol 30: 3077-3083, 2012.

26. Gerlinger M, Rowan AJ, Horswell S, Larkin J, Endesfelder D, Gronroos E, Martinez P, Matthews N, Stewart A, Tarpey P, et al: Intratumor heterogeneity and branched evolution revealed by multiregion sequencing. N Engl J Med 366: 883-892, 2012.

27. Gerlinger M, Horswell S, Larkin J, Rowan AJ, Salm MP, Varela I, Fisher R, McGranahan N, Matthews N, Santos CR, et al: Genomic architecture and evolution of clear cell renal cell carcinomas defined by multiregion sequencing. Nat Genet 46: 225-233, 2014.

28. Zhang J, Fujimoto J, Zhang J, Wedge DC, Song X, Zhang J, Seth S, Chow CW, Cao Y, Gumbs C, et al: Intratumor heterogeneity in localized lung adenocarcinomas delineated by multiregion sequencing. Science 346: 256-259, 2014.

29. de Bruin EC, McGranahan N, Mitter R, Salm M, Wedge DC, Yates L, Jamal-Hanjani M, Shafi S, Murugaesu N, Rowan AJ, et al: Spatial and temporal diversity in genomic instability processes defines lung cancer evolution. Science 346: 251-256, 2014

30. Lee SY, Kim MJ, Jin G, Yoo SS, Park JY, Choi JE, Jeon HS, Cho S, Lee EB, Cha SI, et al: Somatic mutations in epidermal growth factor receptor signaling pathway genes in non-small cell lung cancers. J Thorac Oncol 5: 1734-1740, 2010.

31. Benedettini E, Sholl LM, Peyton M, Reilly J, Ware C, Davis L, Vena N, Bailey D, Yeap BY, Fiorentino M, et al: Met activation in non-small cell lung cancer is associated with de novo resistance to EGFR inhibitors and the development of brain metastasis. Am J Pathol 177: 415-423, 2010.

32. Yano S, Yamada T, Takeuchi S, Tachibana K, Minami Y, Yatabe Y, Mitsudomi T, Tanaka H, Kimura T, Kudoh S, et al: Hepatocyte growth factor expression in EGFR mutant lung cancer with intrinsic and acquired resistance to tyrosine kinase inhibitors in a Japanese cohort. J Thorac Oncol 6: 2011-2017, 2011.

33. Ludovini V, Bianconi F, Pistola L, Chiari R, Minotti V, Colella R, Giuffrida D, Tofanetti FR, Siggillino A, Flacco A, et al: Phosphoinositide-3-kinase catalytic alpha and KRAS mutations are important predictors of resistance to therapy with epidermal growth factor receptor tyrosine kinase inhibitors in patients with advanced non-small cell lung cancer. J Thorac Oncol 6: 707-715, 2011.

34. Shih JY, Gow CH and Yang PC: EGFR mutation conferring primary resistance to gefitinib in non-small-cell lung cancer. N Engl J Med 353: 207-208, 2005.

35. Rolfo C, Castiglia M, Hong D, Alessandro R, Mertens I, Baggerman G, Zwaenepoel K, Gil-Bazo I, Passiglia F, Carreca AP, et al: Liquid biopsies in lung cancer: The new ambrosia of researchers. Biochim Biophys Acta 1846: 539-546, 2014. 